Trivent Publishing

(C) The Authors, 2016

Available online at http://trivent-publishing.eu/

Engineering and Industry Series

Volume Power Systems, Energy Markets and Renewable Energy Sources in

South-Eastern Europe

\title{
Assessment of the implementation of Guarantees of Origin (GOs) in Europe
}

\author{
Konstantinos Gkarakis, ${ }^{1,2}$ Athanasios Dagoumas ${ }^{2}$
}

\footnotetext{
${ }^{1}$ RES Lab, Dpt. of Energy Technology Engineering, Faculty of Technological Applications, Technological Educational Institute (TEI) of Athens, 17, Greece, ape@teiath.gr

${ }^{2}$ Dpt. of International and European Studies, School of Economics, Business and International Studies, University of Piraeus, Greece, dagoumas@ unipi.gr
}

\begin{abstract}
The aim of the paper is to provide an analysis about the operation of Guarantees of Origin (GOs) from renewable energy sources (RES) in the European Union. It provides a description of the different schemes that have been elaborated and provides an assessment of their effectiveness as a tool for diffusion of green electricity in the energy mix. It examines the benefits and limitations of the GOs for different categories of market participants: providers/suppliers and end users of electricity. Moreover, it provides suggestions for the better functioning of the GO system. The paper concludes that voluntarily purchased renewable electricity products like GOs may create an increase in the demand of renewable electricity by end-customers.
\end{abstract}

\section{Keywords}

Guarantees of Origin (GOs); electricity market; disclosure of the energy mixture; renewable energy provided original work is properly cited and that this is not done for commercial purposes. Users may not remix, transform, or build upon the material and may not distribute the modified material (http://creativecommons.org/licenses/by-nc/4.0/) 


\section{Introduction}

The European Union perceived the consequences of the climate change, has taken immediate measures in order to control initially and reduce the pollution. Some important actions in this direction are the European register of emissions and targets on the reduction of certain pollutants. By EU directive of 2003 set the foundations for emissions trading and in 2005 the first results showed the success of the measures. In January 2008 the European Union, compliant with the Kyoto Protocol, promotes the use of renewable energy by adopting the socalled "20-20-20" targets: For all the EU Member-States by 2020 provided the following binding legislative energy targets for 2020

-20\% cut in greenhouse gas emissions (from 1990 levels)

-20\% of EU energy from renewables

-20\% improvement in energy efficiency

The 2030 climate and energy framework sets three key targets for the year 2030 [1]:

- At least 40\% cuts in greenhouse gas emissions (from 1990 levels)

- At least 27\% share for renewable energy

- At least $27 \%$ improvement in energy efficiency

With this strategy the EU has the dual objective of greater security of energy supply and the reduction of greenhouse gas emissions sought to achieve. This design, among other things, initiated procedures to redefine the studies, the pricing and access to electricity grids, promoting renewable energy sources.

The liberalization of the energy market, signifies to the consumer that could be choose the provider of electric energy, have options in the pricing cost of the offered $\mathrm{kWh}$, compare the services of the provider, and choose the source and/or the mixture of electricity will consume. This liberalization leads the electricity supply energy companies in a healthy competition, to offer a greatest possible "green" energy mix electricity to attract new environmentally sensitized consumers and industries, offering tariff rates that are in line with high offered services, environmental protection and sustainability.

Electricity has traditionally represented a product supplied through homogeneous markets as it is impossible to physically distinguish one unit of electricity taken from the grid from another. At the same time, these units of electric energy have been fed into the grid from production plants with very different environmental loads as well as different resource costs.

It should be mentioned that according to the source of energy adopted various forms of Guarantees of Origin (GOs) or Energy Certificates. The most popular and commercial bankable energy certificate is the Guarantee of Origin from Renewable Energy Sources. In addition there are Guarantees of Origin from other energy sources like coal, nuclear energy etc.

GOs for renewable energy negotiate and redeem in international energy exchanges and in secondary markets so that providers and energy suppliers to use as evidence to their customers about the origin and quality of supplied 
electricity. Also, large industries and brands bought them in order to certify the use of renewable energy sources for the production of their products and to declare so, their active participation in the sustainability and environmental protection of the planet.

The aim of the paper is to provide an analysis about the operation of Guarantees of Origin (GOs) from renewable energy sources (RES) in the European Union. It provides a description of the different schemes that have been elaborated in each Member State and provides an assessment of their effectiveness as a tool for diffusion of green electricity in the energy mix. It examines the benefits and limitations of the GOs for different categories of market participants: providers/suppliers and end users of electricity. Moreover, it provides suggestions for the better functioning of the GO system.

\section{Electricity Disclosure and Tracking electricity systems}

\section{A. Electricity disclosure and GOs}

Electricity cannot be tracked along the electricity grid. Thus, consumers cannot have the guarantee that they really get power from a specific supplier/producer or from a specific power plant. Electricity cannot be counted and separated like grains of rice: all the electricity produced from different sources is mixed in the same conductor or cable. When use "tracking of electricity" we mean all mechanisms which are being used in order to account for certain volumes of electricity generation and their generation attributes, such as the energy source and technology used for power production, related $\mathrm{CO} 2$ emissions etc.

The main purposes for which tracking is currently being used [2], [3], [4]:

- The provision of information to final consumers for electricity disclosure as prescribed by Directive 2003/54/EC, its update in Directive 2009/72/EC and national regulations. Electricity disclosure means that all suppliers of electricity disclose to their consumers the origin of the electricity which they are supplying in terms of the energy sources used for power generation, related $\mathrm{CO} 2$ emissions and radioactive waste produced.

- European governments have committed themselves to fulfil quantitative national targets for the share of renewable energy in overall energy consumption. Such targets apply for RES-E in the year 2010 under the "old" RES Directive 2007/77/EC and more generally for renewable energy for the years 2011 to 2020 under the "new" RES Directive 2009/28/EC.

GOs is the most widespread and important tracking system in Europe, implemented in the form of transferable electronic certificates, de-linked from the electricity market. When introducing Guarantee of Origin (GO) and Electricity Disclosure according to the European Renewable Energy Directive (2009/26/EC) and Electricity Market Directive (2009/72/EC), respectively, the issue regarding which electricity models should be assumed for one particular 
electricity customer gets more complicated as these means allow the distinction between the physical electricity and the related environmental attributes.

A GO is defined as a means of proving the origin of electricity, while the objective of the Electricity Disclosure is to provide consumers with relevant information about power generation and to allow for informed consumer choice, not only based on electricity prices. The suppliers of electricity are required to disclose their electricity portfolio with regards to energy source and environmental impacts, specifying the emissions of $\mathrm{CO} 2$ and the amount of radioactive waste. The disclosed information is often referred to as the environmental attributes [5].

GOs can be voluntarily purchased by any customer with the scope to claim the related attributes (origin, emissions etc.) of the generated electricity, thus improving the Electricity Disclosure.

The remaining electricity customers have to use the Residual Mix for disclosure (as figure 1 shows).

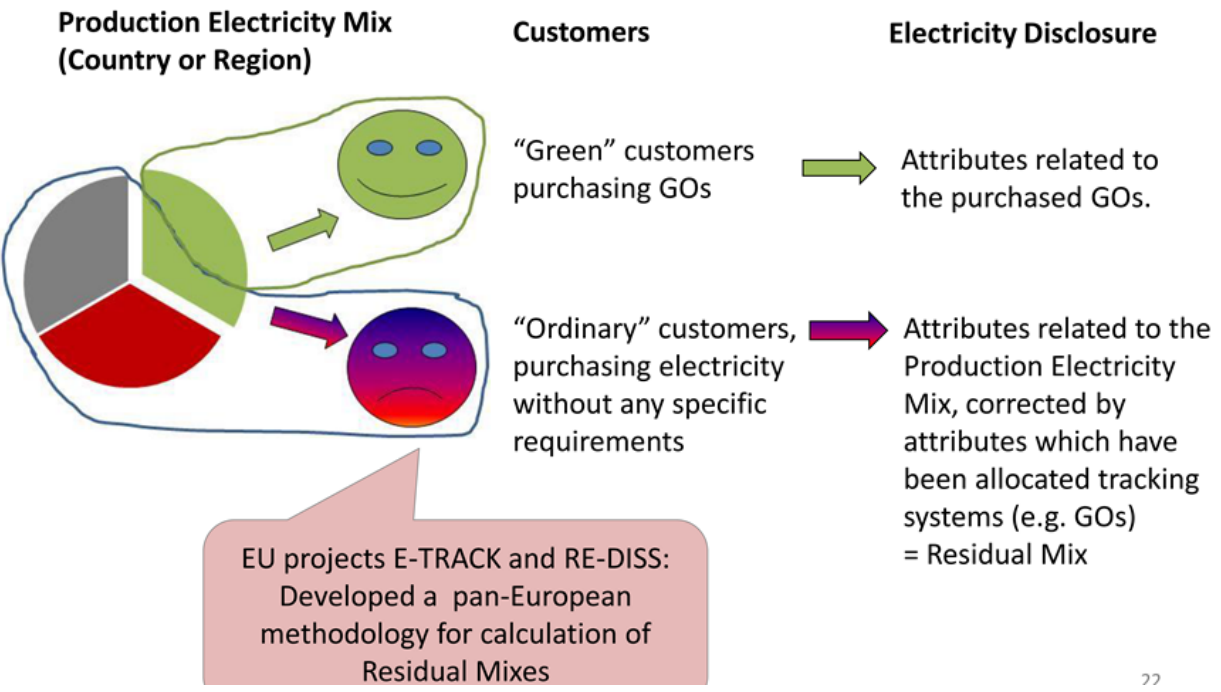

Fig. 1. Connection GOs and electricity disclosure.

As an example of GOs operation (exporting GOs) in a country Residual Mix is illustrated in the figure 2 . 

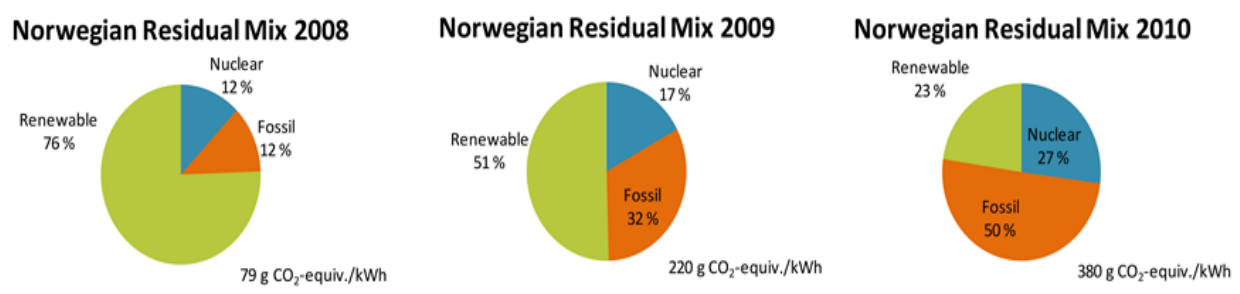

Fig. 2. The Norwegian Electricity Disclosure 2008 - 2010, calculated on the basis of the European harmonised E-TRACK methodology [6], [7].

\section{B. Tracking electricity systems and GOs}

The implementation of GOs, representing a tracking instrument for proving the origin of electricity, opens up the possibilities of separating the produced electricity which is covered by GOs from the rest of the electricity production. A GO is similar to a label on a bottle: it carries information telling the consumer facts about the product. Controlling the information and the accuracy of the guarantee of origin is therefore of critical importance. A unique body (e.g. an electricity regulator or a transmission system operator) is usually granted this authority for a given domain.

In their most accomplished form, Guarantees of Origin are issued electronically for a controlled quantity of electricity generation (usually $1 \mathrm{GO}$ per MWh), traded and redeemed (i.e. used) by suppliers as evidence to their customers of the quality of the delivered electricity. Generation from renewable energy sources is the most sought-after attribute. A new development concerns guarantees of origin for cogeneration heat plants (or CHP). Some countries already have guarantees of origin issued for all types of electricity generation (nuclear, coal, solar, biomass). Possible extensions also include fair-trade, $\mathrm{CO} 2$ statistics etc.

The GO system is a book and claim system which enables the consumer to voluntarily purchase GOs to claim the specific energy source of the consumed electricity [8]. It can be used as an information carrier for further information according to specific green power labels.

An important effect of the implementation of the GO system is that the traditional electricity product has been divided into two separate products: (i) the environmental attributes related to the generation of the electricity, and (ii) the physical electricity being delivered. The implementation of this voluntary and regulated trading system thus means that the GOs are sold in a market which is separated from the physical electricity market. The principle for this system is illustrated in figure 3 . 


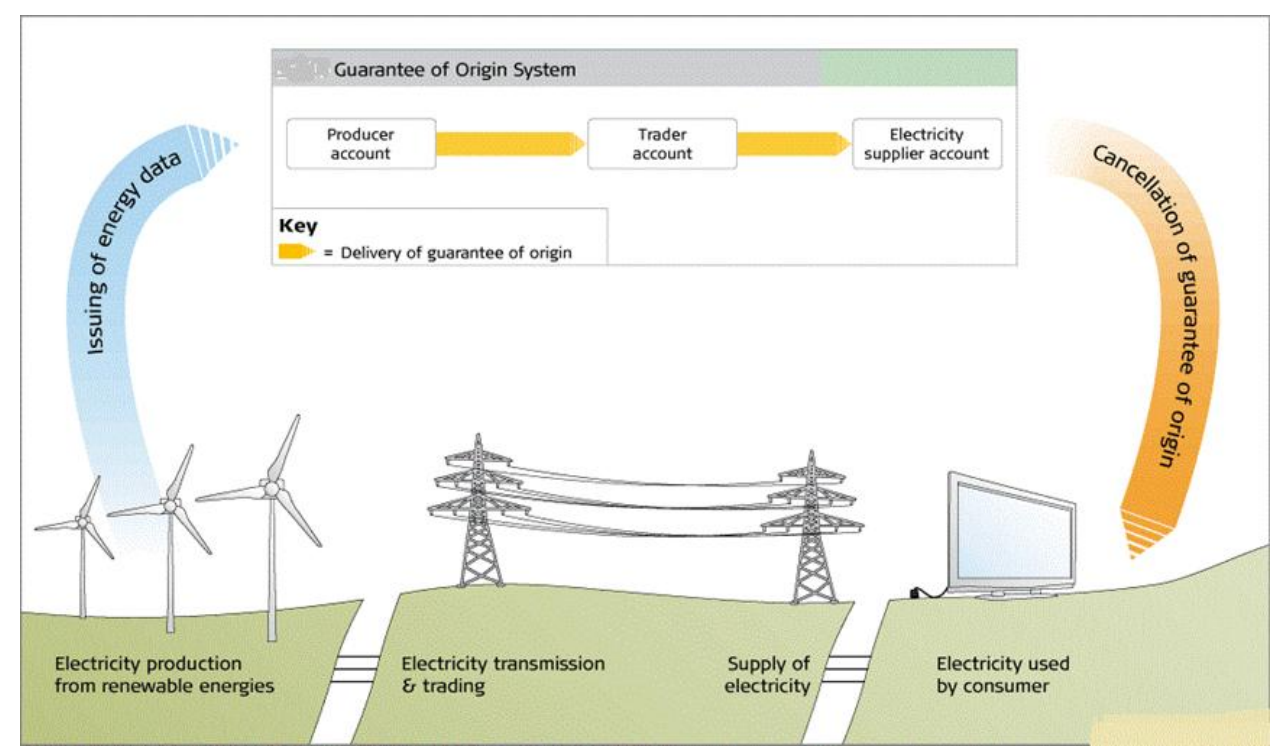

Fig. 3. The principle of GOs system operation.

\section{GOs and their usage}

\section{A. GOs in European legislation}

GOs in the meaning of Directive 2009/28/EC are the only precisely defined instruments evidencing the origin of electricity generated from renewable energy sources.

All EU member States are required to establish and maintain a GOs scheme. The purpose of this scheme is to promote and increase the contribution of RES to electricity production across the $\mathrm{EU}$, providing a common platform to facilitate the trade of renewable electricity between member States. Also this scheme sets out increased transparency to consumers, allowing to choice to purchase renewable or non-renewable electricity.

A GO regime was created by Directive 2001/77/EC in order to facilitate domestic or international trade in renewable electricity (i.e. proof of the green nature of the electricity) and to increase transparency in consumers' choice between renewable and non-renewable electricity.

Article 5 of the Directive introduces a minimum set of requirements for the GO. The GO must specify the source, date and place of production in a reliable manner; it should be mutually recognised by all Member States exclusively as proof of renewably sourced electricity, and it should be reliable and accurate. The GO can be used for a number of purposes, including claiming subsidy (a feed in tariff or green certificate payment), supporting electricity bill energy mix "disclosure" (In accordance with Article 3(6) of Directive 2003/54/EC, Member States are required to implement a scheme for the disclose of the fuel mix.), and 
proving compliance with national renewable energy obligations. However, these applications are voluntary. Guarantees of origin are tradable across EU member states.

Member States shall ensure that a guarantee of origin is issued in response to a request from a producer of electricity from renewable energy sources. Member States may arrange for guarantees of origin to be issued in response to a request from producers of heating and cooling from renewable energy sources. Such an arrangement may be made subject to a minimum capacity limit. A guarantee of origin is the standard size of $1 \mathrm{MWh}$. No more than one guarantee of origin shall be issued in respect of each unit of energy produced.

\section{B. GOs - a capability for electricity consumers to demand renewable energy}

GO is not just one more "paper", is actually a main tracking instrument for proving the origin of electricity in Europe, in accordance with two central EU Directives (the Renewable Energy Directive (2009/28/EC and the Electricity Market Directive (2009/72/EC)). Each GO represents proof that $1 \mathrm{MWh}$ of renewable energy has been produced and embodies the environmental benefits of that amount of renewable energy generated.

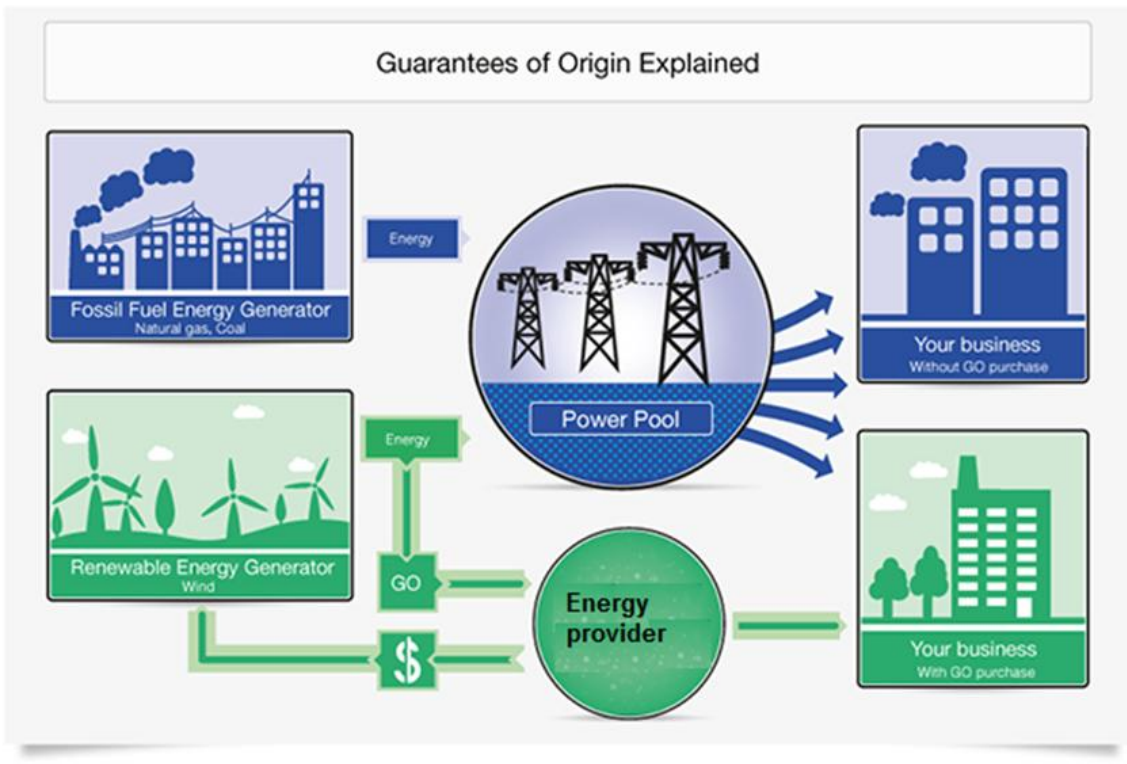

Fig. 4. The basic operation of GOs.

GOs represent a mechanism which gives customers the opportunity to select an electricity product based on environmental requirements. The system thus creates a mechanism for a customer driven demand for renewable electricity 
which, in the long-term, may influence the decisions of renewable energy investors [9]. Such a system fits well into the logic of a liberalised market where communication between suppliers and customers becomes a key element [10]. The GO system has shown that there is an existing and increasing market which is willing to pay the extra costs for renewable electricity, thus generating extra income for the energy companies, which can be invested in new power plants.

GOs represent a mechanism that gives customers the opportunity to select an electricity product based on environmental requirements, in addition to price. By purchasing GOs, customers are given a proof of the origin of the electricity, thus being able to use emission factors related to the specifically purchased electricity generation technology. The GOs system is a reliable and regulated way which provides to customers the possibility of demanding renewable electricity and helps the funding of new renewable energy power plants.

\section{GOs and TGCs}

The EU Emission Trading Scheme (ETS) aims to reduce greenhouse gas (GHG) emissions, the Tradable Green Certificate or Green Certificates (TGC) system's objective is to increase the generation of renewable energy, while the goal of Electricity Disclosure and GOs is to provide consumers with relevant information about the generated electricity [11].

It is important to emphasise that the GO system represents a voluntary, but regulated market, while the TGC system represents a mandatory market. The mandatorily purchased of TGCs affect national production mix and voluntarily purchased GOs affect individual consumption mix.

Price setting for electricity and TGC is driven by the demand for energy and, in the case of TGC, is also affected by the predetermined quota levels. The GOs market is linked to other needs, such as the customer's willingness to document the environmental performance of products and services. The fact that GO prices are set in a market which is separated from the TGC and power market may not therefore reduce the long-term incomes from the sale of TGC and power, in spite of increased income from the sale of GOs [11].

In summary, the GOs and electricity disclosure system may increase the total production of electricity from RES by leading to increase TGC targets. Thus changes in RES electricity generation might be helped by mandatory and voluntary markets working in parallel. On the basis of this, the GO, Electricity Disclosure and TGC mechanisms represent discrete elements of an overall package of policy instruments, which together may lead to increased renewable electricity generation at the expense of fossil generation.

\section{European Energy Certificate System (EECS-GO)}

The existence of a recognized European body which can specify, monitor and control with transparency and credibility of the system the transfer of guarantees 
of origin from renewable sources and their final cancellation in favor of an end consumer, it is vital for the value of the certificates, avoidance of duplicate entries and for statistical monitoring the reduction from polluting energy sources. The European Union, through a body AIB (Association of Issuing Bodies) develops and promotes a standardized system of guarantees of origin, the called "European Energy Certificate System" (EECS-GO), so that there are structures and processes that ensure reliable operation of European System of Guarantees of Origin. The European Energy Certification System (EECS) is a harmonised system for international trade of renewable energy certificates, such as GOs. EECS has been developed by the AIB, which is the leading enabler of international energy certificate schemes. Currently. as shown in Figure 5, AIB has 21 members, representing 19 European countries (as each of the 3 Belgian regions has it owns issuing bodies) [12].

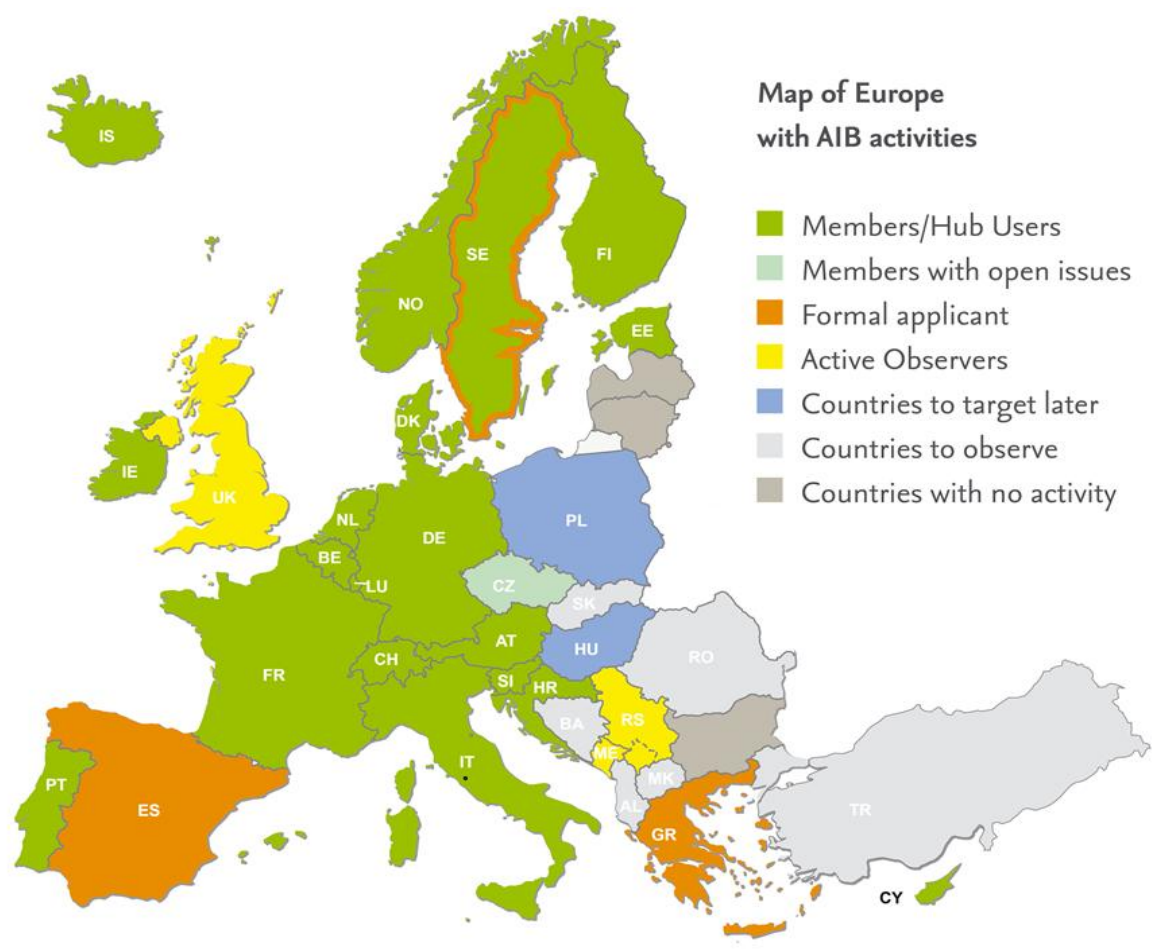

Fig. 5. Map of Europe with AIB activities.

EECS market activity continues to increase the last few years, with a large increase in the quantity of certificates that used by the suppliers to prove the source of the consumed electricity. This leads to continued increase in internal transfer, international trade and cancelations of the issued certifications. Over the years, more and more certificates find a value, growing the market [13], [14].The figure 6 show the annual quantity of certificates issued, cancelled and 
expired for production during that year; and those that have been issued, transferred within a country, transferred internationally, expired and cancelled during that year.

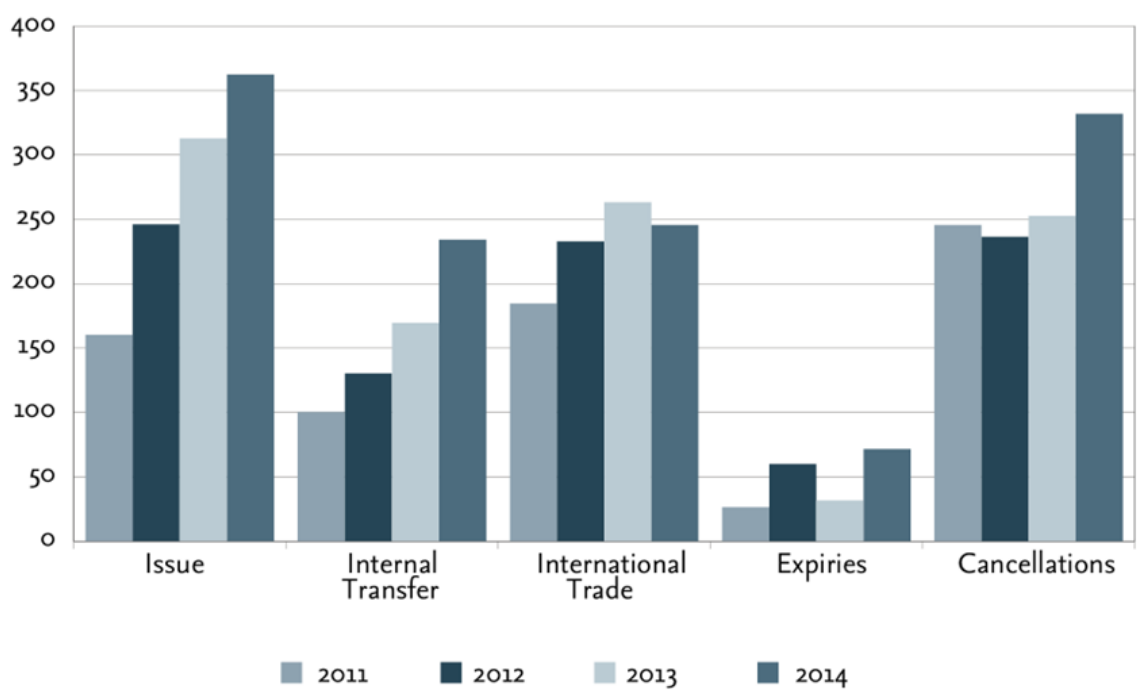

Fig. 6. Annual EECS transactions by transaction date (TWh).

\section{Conclusion and proposals}

National rules and regulations on GOs differ considerably though they are all based on same European Directives. AIB and RE-DISS have played an important role in harmonizing over Europe, but there is still work to be done e.g. regarding the acceptance of foreign GOs, the connection to AIB-hub, the problematic situation in some countries etc.

The implementation of GO in all countries in Europe should be based on the European Energy Certificate System (EECS) operated by the Association of Issuing Bodies (AIB). In case those national GO systems are established outside of EECS, then EECS should at least be used for transfers between registries.

The integration of European electricity market should be accompanied by the development of a European GO-market. This market could first be developed for RES-GOs and later extended to other kinds of GOs. Trading participants have the possibility to trade three different European GO-products up to three years before delivery. It is our aim to establish a European market for GOs. Already today, GO-trading companies as well as GO-producers and utilities using GOs are spread all over Europe. However, market development is hindered by differing national regulations on GOs. The final aim will be the developing a European market for GOs accompanying the European electricity market, in order to pave way for the Energy Union. 


\section{References}

[1] Presidency Conclusions of the European Council, Brussels on 23/24.10.2014, p. 1-15, available at:

http://www.consilium.europa.eu/uedocs/cms data/docs/pressdata/en/ec/145 397.pdf

[2] Timpe, Christof (2007): A European Standard for the Tracking of Electricity. Final report from the E-TRACK project, August 2007. Available for download from the E-TRACK website: http://www.e-trackproject.org/documents.php.

[3] Lise, Wietze, Timpe, Christof, Jansen, Jaap C., ten Donkelaar, Michael (2007): Tracking electricity generation attributes in Europe, Energy Policy 35 (2007) 5855-5864.

[4] Lescot, Diane (2009): The policy framework for electricity disclosure and the Green Energy market. Presentation given at the E-TRACK II conference, Brussels, 26 June 2009. Available for download from the ETRACK website: http://www.e-track-project.org/events.php.

[5] Raadal, H.L., 2012. Guarantees of Origin (GOs). Applications in LCA. Report Ostfold Research, AR 03.12.

[6] Jakobsson, S., 2010. Results of Updated RM Calculations for 2009. Presentation at the 2nd Workshop "Making Guarantees of Origin and Electricity Disclosure in Europe more reliable", July 2010, Brussels.

[7] Klimscheffskij, M., 2011. Results of the Calculation for Residual Mixes in 2010. Presentation at the 4th Workshop "Making Guarantees of Origin and Electricity Disclosure in Europe more reliable", May 2011, Brussels.

[8] RECS International. Homepage. Available at: http://www.recs.org/.

[9] Raadal, H.L. \& Svanes, E., 2012. Feedback on the GHG Power Accounting Guidelines Draft of February 14th 2012, Available at: http://ostfoldforskning.no/prosjektsider/49/energy\%20trading\%20and\%20t he\%20environment $\% 202020 /$ nyhet/33/feedback on the ghg power accou nting_guidelines.aspx

[10] Markard, J. \& Truffer, B., 2006. The promotional impacts of green power products on renewable energy sources: direct and indirect eco-effects. Energy Policy, 34(3), pp.306-321.

[11] Raadal, H.L.,2013. Greenhouse gas emissions from electricity generation systems. Tracking and claiming in environmental reporting, $\mathrm{Ph} . \mathrm{D}$. thesis, Norwegian University of Life Sciences.

[12] AIB. Joining the AIB. 2015. Available at: http://www.aibnet.org/portal/page/portal/AIB_HOME/AIB/How_to_join/Joining\%20AIB \%202015\%20release\%20v1.pdf 
[13] AIB, 2014. AIB (Association of Issuing Bodies) Annual report 2014. Available at: http://www.aibnet.org/portal/page/portal/AIB_HOME/NEWSEVENTS/Annual_reports.

[14] ECOFYS. Renewable energy progress and biofuels sustainability, 2014. Annex E. Available at:

https://ec.europa.eu/energy/sites/ener/files/documents/Final\%20report\%20November\%202014.pdf 